\title{
MEMBANGUN KEMAMPUAN KOMUNIKASI MATEMATIS DALAM PEMBELAJARAN MATEMATIKA
}

\author{
Disusun oleh : \\ Wahid Umar \\ Program Studi Pendidikan Matematika \\ FKIP Universitas Khairun Ternate
}

\begin{abstract}
Abstrak:
Sampai saat ini peran guru dalam membangun kemampuan komunikasi matematis siswa khususnya dalam pembelajaran matematika masih sangat terbatas. Kemampuan komunikasi merupakan aspek yang sangat penting yang perlu dimiliki oleh siswa yang ingin berhasil dalam studinya. Senada dengan itu, menurut Kist (Clark, 2005) kemampuan komunikasi yang efektif merupakan kemampuan yang perlu dimiliki oleh siswa untuk semua mata pelajaran.

Kemampuan komunikasi matematis (mathematical communication) dalam pembelajaran matematika sangat perlu untuk dikembangkan. Hal ini karena melalui komunikasi matematis siswa dapat mengorganisasikan berpikir matematisnya baik secara lisan maupun tulisan. Di samping itu, siswa juga dapat memberikan respon yang tepat antar siswa dan media dalam proses pembelajaran. Bahkan dalam pergaulan bermasyarakat, seseorang yang mempunyai kemampuan komunikasi yang baik akan cenderung lebih mudah beradaptasi dengan siapa pun dimana dia berada dalam suatu komunitas, yang pada gilirannya akan menjadi seorang yang berhasil dalam hidupnya.

Dalam tulisan ini, penulis menyajikan tentang pengertian kemampuan komunikasi matematis, dengan cakupan dua hal yakni kemampuan siswa menggunakan matematika sebagai alat komunikasi (bahasa matematika), dan kemampuan siswa mengkomunikasikan matematika yang dipelajari sebagai isi pesan yang harus disampaikan. Bagaimana dan mengapa komunikasi penting untuk membangun suatu komunitas matematis melalui jalur komunikasi terbuka di dalam kelas.
\end{abstract}

Kata kunci : komunikasi matematis, matematika sebagai bahasa, aktivitas sosial

Dalam upaya mengantisipasi perkembangan ilmu pengetahuan dan teknologi yang semakin maju, pembelajaran matematika di kelas perlu direformasi, (Tandaliling, 2011). Tugas dan peran guru bukan lagi sebagai pemberi informasi (transfer of knowledge), tetapi sebagai pendorong siswa belajar (stimulation of learning) agar dapat mengkonstruksi sendiri pengetahuan melalui berbagai aktivitas termasuk aspek berkomunikasi. Menurut Silver dan Smith (1996: 20) mengutarakan bahwa tugas guru adalah: (1) melibatkan siswa dalam setiap tugas matematika; (2) mengatur aktivitas intelektual siswa dalam kelas seperti diskusi dan komunikasi; (3) membantu siswa memahami ide matematika dan memonitor pemahaman mereka. 
Pandangan kedua ahli Silver dan Smith ternyata kemampuan komunikasi matematis memang perlu ditumbuhkembangkan di kalangan siswa. Hal ini diperkuat oleh Baroody (1993: 107), bahwa pembelajaran harus dapat membantu siswa mengkomunikasikan ide matematika melalui lima aspek komunikasi yaitu representing, listening, reading, discussing dan writing. Selanjutnya disebutkan sedikitnya ada dua alasan penting, mengapa komunikasi dalam pembelajaran matematika perlu ditumbuhkembangkan di kalangan siswa. Pertama, mathematics as language, artinya matematika tidak hanya sekedar alat bantu berpikir ( a tool to aid thinking), alat untuk menemukan pola, menyelesaikan masalah atau mengambil kesimpulan, tetapi matematika juga "an invaluable tool for communicating a variety of ideas clearly, precisely, and succinctly. Kedua, mathematics learning as social activity: artinya, sebagai aktivitas sosial dalam pembelajaran matematika, sebagai wahana interaksi antar siswa, serta sebagai alat komunikasi antara guru dan siswa.

Di sisi lain, Greenes dan Schulman (1996: 168) yang mengatakan bahwa komunikasi matematik merupakan: (I) kekuatan sentral bagi siswa dalam merumuskan konsep dan strategi matematik, (2) modal keberhasilan bagi siswa terhadap pendekatan dan penyelesaian dalam eksplorasi dan investigasi matematik, (3) wadah bagi siswa dalam berkomunikasi dengan temannya untuk memperoleh informasi, membagi pikiran dan penemuan, curah pendapat, menilai dan mempertajam ide untuk meyakinkan orang lain.

Dengan demikian, kemampuan komunikasi matematis sebagai salah satu aktivitas sosial (talking) maupun sebagai alat bantu berpikir (writing) yang direkomendasi para pakar agar terus ditumbuhkembangkan di kalangan siswa. Komunikasi memainkan peranan sentral dalam "Professional Teaching Standards" NCTM, karena "mengajar adalah mengkomunikasikan." (Jacob, 2003:2). Gagasan dokumen itu merupakan contoh bagaimana kita mengkomunikasikan apa yang kita ketahui tentang belajar siswa dengan berbagai audiens. Ini merupakan hubungan antara tujuan assessmen dengan apa dan bagaimana kita berkomunikasi. Komunikasi merupakan esensi dari mengajar, assessing, dan belajar matematika. Apabila mengajar, kita membutuhkan aktivitas-aktivitas, a.l. misalnya, kita perlu untuk mendengarkan. Kita perlu mendengarkan untuk apa siswa mengerti, untuk apa mereka mengetahui, dan untuk apa mereka berpikir tentang matematika dan belajar matematika.

Ada dua alasan penting mengapa pembelajaran matematika terfokus pada pengkomunikasian. Pertama, matematika pada dasarnya adalah suatu bahasa -- bahasa kedua. Kedua, matematika dan belajar matematis dalam bathinnya merupakan aktivitas sosial. 


\section{Komunikasi Matematika: Aspek Penting Yang Perlu Perhatian}

Berbagai sumber juga menyebutkan tentang peran penting komunikasi dalam pembelajaran matematika (NCTM, 1996, 2000b; Cai, 1996; Baroody, 1993; Miriam, dkk, 2000; Karen, dkk, 2000; Sandra, 1999, David, 2000, Pugalee, 2001, Knuth, 2001)

Pengungkapan pentingnya komunikasi dalam pembelajaran matematika, dapat ditemukan pula dalam berbagai buku pelajaran matematika di Amerika Serikat. Misalnya, dalam buku Connected Mathematics dituliskan bahwa The Overarching Goal of Connected Mathematics adalah "All students should be able to reason and communicate proficiently in mathematics" (Lappan, 2002). Sedangkan dalam buku Mathematics: Applications and Connections disebutkan salah satu tujuan yang ingin dicapai adalah memberikan kesempatan seluasluasnya kepada para siswa untuk mengembangkan dan mengintegrasikan keterampilan berkomunikasi melalui modeling, speaking, writing, talking, drawing, serta mempresentasikan apa yang telah dipelajari (Collins, dkk, 1995).

Kurikulum "Nasional 2006" yang berbasiskan sesuai tingkat satuan pendidikan baik untuk tingkat SD, SMP maupun SMA juga mengedepankan kemampuan komunikasi matematika sebagai salah satu kemampuan dasar yang perlu dimiliki siswa.

Menurut Baroody (1993), pada pembelajaran matematika dengan pendekatan tradisional, komunikasi (lisan) siswa masih sangat terbatas hanya pada jawaban verbal yang pendek atas berbagai pertanyaan yang diajukan oleh guru. Bahkan menurut Cai (1996) 'it is so rare for students to provide explanation in mathematics class, so strage to talk about mathematics, and so surprising to justify answer.'

Komunikasi matematika perlu menjadi fokus perhatian dalam pembelajaran matematika, sebab melalui komunikasi, siswa dapat mengorganisasi dan mengkonsolidasi berpikir matematisnya (NCTM, 2000a), dan siswa dapat meng'explore' ide-ide matematika (NCTM, 2000b). Selain itu menurut Atkins (1999) komunikasi matematika secara verbal (mathematical conversation) merupakan "a tool for measuring growth in understanding, allow participants to learn about the mathematical constructions from others, and give participants opportunities to reflect on their own mathematical understandings."

Kesadaran tentang pentingnya memperhatikan kemampuan siswa dalam berkomunikasi dengan menggunakan matematika yang dipelajari di sekolah perlu ditumbuhkan, sebab salah satu fungsi pelajaran matematika adalah sebagai cara mengkomunikasikan gagasan secara praktis, sistematis, dan efisien. Atau dalam istilah Baroody (1993): "an invaluable tool for communicating a variety of ideas clearly, precisely, and succintly." 
Menurut Baroody (1993) sedikitnya ada 2 alasan penting yang menjadikan komunikasi dalam pembelajaran matematika perlu menjadi fokus perhatian yaitu (1) mathematics as language; matematika tidak hanya sekedar alat bantu berpikir (a tool to aid thinking), alat untuk menemukan pola, atau menyelesaikan masalah namun matematika juga "an invaluable tool for communicating a variety of ideas clearly, precisely, and succintly," dan (2) mathematics learning as social activity; sebagai aktivitas sosial, dalam pembelajaran matematika, interaksi antar siswa, seperti juga komunikasi gurusiswa merupakan bagian penting untuk "nurturing children's mathematical potential". Bahkan menurut Cai (1996) "communication is considered as the means by which teachers and students can share the process of learning, understanding, dan doing mathematics."

\section{Peran Guru Dalam Meningkatkan Komunikasi Matematika di Kelas}

Menurut Cobb dalam (Sandra, 1999), dengan mengkomunikasikan pengetahuan yang dimiliki siswa, dapat terjadi renegosiasi respon antar siswa, guru hanya berperan sebagai "filter". Cai dan Patricia (2000) berpendapat bahwa guru dapat mempercepat peningkatan komunikasi matematika dan penalaran siswa dengan cara memberikan tugas matematika dalam berbagai variasi. Menurut Susan (1996) komunikasi matematika akan berperan efektif manakala guru juga mengkondisikan siswa agar 'mendengarkan secara aktiflisten actively' sebaik mereka mempercakapkannya.

Peran guru untuk menciptakan komunitas matematika di kelas juga sangat strategis, dalam arti bahwa porsi peran guru sebagai "pengajar" harus proporsional dengan peran lain sebagai fasilitator, partisipan atau bahkan sebagai seorang sahabat di kelas. Dalam Prinsip dan Standar Matematika Sekolah (NCTM, 2000a) ditegaskan bahwa untuk mensupport pembelajaran agar efektif, guru harus membangun komunitas di kelas sehingga para siswa merasa bebas untuk mengekspresikan pemikirannya.

Upaya menciptakan komunitas matematika yang kondusif bagi tumbuh kembangnya kemampuan berkomunikasi dengan menggunakan matematika, dapat dilakukan dengan berbagai jenis aktivitas, antara lain: (i) pemberian tugas yang bersifat open - ended task, yang memungkinkan siswa menunjukkan proses dan menjelaskan alasan pengerjaannya (Cai,1996), (ii) melalui cooperative learning (Nodding dalam Baroody, 1993; Artzt, 1996), (iii) penggunaan metode proyek (Wanda, 1997), (iv) pengajuan masalah oleh siswa (Riedesel, 1990), (v) dengan menerapkan strategi pembelajaran "think-talkwrite" (Huinker, 1996), dan (vi) dengan menerapkan strategi "explain-build-go beyond" (Sherin, 2000b). 


\section{Komunikasi Matematika, Pemahaman Matematika dan Pemecahan Masalah}

Dikemukakan dalam NCTM (2000a) bahwa pemahaman matematika secara konseptual dapat dibangun melalui pemecahan masalah, penalaran dan argumentasi. Pemaknaan argumentasi dalam hal ini tentu melibatkan kemampuan berkomunikasi baik lisan maupun tertulis. Dengan menggunakan istilah multiple eksplanasi, untuk menyebut berbagai cara berkomunikasi, Whitin (2000b) mengemukakan bahwa dengan mendorong siswa untuk dapat menjelaskan dengan berbagai cara, seorang guru tidak hanya memvalidasi "the invidual voices" siswa tetapi membangun "a rich fabric" dari pemahaman matematika siswa.

Penegasan Within di atas memberikan pengertian bahwa komunikasi baik lisan, tertulis, demonstrasi maupun representasi dapat membawa siswa pada pemahaman yang mendalam tentang matematika. Secara lebih luas dapat pula disimak satu pertanyaan yang diungkapkan dalam NCTM (1989) yakni "The ability to read, listen, think creatively, and communicate about problem situations, mathematical representations, and the validation of solution will help students to develop and deepen their understanding of mathematics "

Komunikasi matematika tidak hanya dapat dikaitkan dengan pemahaman matematika, namun juga sangat terkait dengan kemampuan pemecahan masalah. Hal ini dapat dicermati antara lain dari pendapat Riedesel (1990) yang mengemukakan bahwa untuk meningkatkan kemampuan dalam pemecahan masalah ada beberapa cara pengungkapan masalah yang dapat dilakukan seperti: masalah dengan jawaban terbuka, masalah dinyatakan dengan menggunakan oral, masalah nonverbal, menggunakan diagram, grafik dan gambar, mengangkat masalah yang tidak menggunakan bilangan, menggunakan analogi, dan menggunakan perumusan masalah siswa.

Variasi dalam pengungkapan masalah, yang implementasinya nampak dalam berbagai tugas yang disiapkan siswa sejalan dengan tujuan aktivitas pemecahan masalah sebagaimana pendapat Annete (1999) yaitu bahwa guru dapat menggunakan aktivitas pemecahan masalah untuk tujuan ganda seperti mengembangkan keterampilan berpikir kritis, keterampilan pengorganisasian data, dan keterampilan komunikasi.

\section{Komunikasi dan Komunitas Matematika Dalam Pembelajaran}

Sebagaimana pengalaman penulis mencermati karakteristik setiap peserta didik dilapangan, terlihat bahwa perhatian terhadap komunikasi matematika siswa sebenarnya sudah "built in," dalam arti bahwa sintak atau langkahlangkah pembelajaran sebenarnya sudah mendukung upaya pengembangan 
kemampuan siswa dalam berkomunikasi. Bagaimana siswa mengkomunikasikan ide-idenya dalam upaya menjawab masalah kontekstual yang diberikan guru, bagaimana siswa berpartisipasi aktif dalam diskusi, negosiasi serta bagaimana siswa "mempertanggung-jawabkan" perolehan jawaban mereka atas pertanyaan terbuka maupun tugas-tugas yang diberikan guru, jelas memerlukan kemampuan untuk mengkomunikasikannya.

Komunitas matematika yang dalam tulisan ini dimaknai sebagai suatu komunitas (dalam kelas) yang menggunakan matematika sebagai "bahan/isi percakapan" - mathematical discourse communties atau disebut pula sebagai discourse communities in mathematics classroom, menurut Silver dan Smith (1996) merupakan tantangan khusus yang menarik bagi para guru.

Banyak diungkapkan (antara lain oleh Heaton, 1994; Wood, Cobb dan Yackel, 1991 dalam Sherin, 1996) bahwa percakapan siswa tentang matematika yang dipelajari di kelas akan membawa pengaruh pula pada cara mengajar guru dan memberi kesempatan guru untuk "rethink" terhadap pemahaman matematika yang mereka miliki. Sejalan dengan hal tersebut, Sherin (2000) mengatakan bahwa untuk meningkatkan kualitas belajar siswa serta untuk membantu guru membuat berbagai perubahan dalam mengajarnya, pengembangan komunitas matematika menjadi sangat penting. Di pihak lain, Baroody (1993) mengemukakan bahwa untuk membangun komunitas matematika di dalam kelas, perlu upaya (i) mengembangkan bahasa komunal - development of communal language, (ii) menerapkan pembelajaran kooperatif, menggalakkan penjustifikasian matematika - mathematical justifications.

Untuk mengenalkan dan menggunakan matematika sebagai bahasa komunikasi pada siswa di sekolah, perlu dilakukan secara hati-hati dan bertahap (sesuai tingkat intelektual peserta didik). Ada 4 saran yang diberikan Baroody dalam kaitannya dengan hal tersebut, yakni (i) gunakan language-experience approach, yakni pendekatan yang didasarkan pada realitas yang meliputi aktivitas: mendengarkan, berbicara, membaca, dan menulis; dalam aktivitas tersebut siswa dipandu untuk mengekspresikan reaksi, ide, dan perasaan berkenaan dengan situasi yang ada di kelas, (ii) definisi dan notasi formal harus dibangun melalui situasi informal, (iii) kaitkan istilah-istilah matematika dengan ekspresi yang dijumpai sehari-hari, (iv) penting bagi siswa untuk dapat membandingkan dan membedakan bahasa matematika dengan bahasa seharihari.

Hal ini diperkuat oleh Artzt (1996) menunjukkan bahwa melalui pembelajaran kooperatif yang dilakukan secara efektif dan melakukan penilaian yang cermat terhadap setiap komunikasi yang terjadi pada setiap aktivitas siswa baik individu maupun kelompok, dapat mengembangkan kemampuan komunikasi 
dalam pemecahan masalah yang dihadapi. Sedangkan upaya menggalakkan justifikasi matematika berkaitan dengan perlunya guru secara rutin menanyakan pada siswa untuk menjustifikasi jawaban dan dugaan yang diperoleh. Hal ini akan membawa siswa pada suatu kebiasaan agar dapat mengkomunikasikan setiap hasil pemikirannya.

Upaya untuk membangun komunitas matematika di kelas juga dilakukan oleh Sherin (2000) dengan menawarkan sebuah model yang disebut sebagai strategi "explain-build-go beyond" yakni suatu strategi yang didesain untuk membantu siswa lebih dari hanya sekedar berbicara tentang matematika tapi percakapan yang produktif tentang matematika. Esensi dari strategi tersebut adalah bagaimana siswa mengkomunikasikan perolehan jawaban terhadap problem yang diberikan guru, kemudian diikuti bagaimana siswa membangun pemahaman berdasarkan berbagai masukan dari siswa lain, dan akhirnya bagaimana siswa dapat mengembangkan jawaban untuk permasalahan yang lebih komplek di seputar masalah tersebut. Selain itu, strategi yang diberikan oleh Huinker (1996) yaitu "think - talk - write" juga menekankan perlunya siswa untuk mengkomunikasikan hasil pemikiran matematikanya.

Kalau dicermati pendapat Sherin dan Huinker tersebut adalah dalam rangkah mengembangkan kemampuan komunikasi merupakan sebuah model sebagai strategi "explain-build-go beyond" yang perlu ditumbuhkembangkan dalam pembelajaran matematika.

Dalam setiap upaya untuk menjawab permasalahan kontekstual yang diberikan guru, setiap siswa tentu akan memulai dengan memikirkan (to think) cara selesaian dengan strategi-strategi informal mereka sendiri. Strategi informal ini merupakan bahan kajian penting karena itu pengarsipan secara tertulis (to write) harus dilakukan sebelum dipercakapkan/ dijelaskan (to explain/ to talk) di kelas. Untuk membangun (to build) pemahaman lebih lanjut, hasil pemikiran siswa tersebut perlu dikonfrontasikan dengan hasil dari siswa lain melalui diskusi, negosiasi, dan sebagainya. Hasil pertukaran pemikiran ini juga perlu diarsipkan secara tertulis. Hal ini dapat digunakan untuk melihat perkembangan pemikiran siswa setelah melalui "uji pertukaran gagasan".

Demikian pula dalam menghadapi masalah kontekstual yang lebih luas dan kompleks (go beyond), siswa harus menuliskan hasil pemikirannya sebelum dikomunikasikan dan didiskusikan lebih lanjut. Bila hal ini dilaksanakan dengan baik, akan terlihat bahwa penciptaan komunitas matematika di kelas sangat akan terakomodasi. Hal ini aktivitas siswa perlu dikondisikan agar mereka dapat berinteraksi sesamanya, diskusi, negosiasi, dan kolaborasi. Pada situasi tersebut, siswa mempunyai kesempatan untuk bekerja, berfikir dan berkomunikasi dengan menggunakan matematika. Menurut Lauren (1999) 
proses komunikasi yang terjadi akan membantu siswa untuk mulai berfikir secara matematis, membangun secara benar keterkaitan matematis, dan "go beyond memorizing rules that have little or no meaning for them".

Berkomunikasi secara cermat, tepat, sistematis dan efisien yang "dilatih" melalui pelajaran matematika, diharapkan dapat menjadi sebuah kebiasaan yang dimiliki siswa dalam kehidupan keseharian mereka. Hal inilah sebenarnya salah satu sumbangan penting komunikasi matematika. Karena itu, berdasarkan uraian di atas, diharapkan para pendidik untuk menumbuhkembangkan kemampuan komunikasi matematika siswa, bukan hanya terjadi di dalam kelas, namun memungkinkan dapat terjadi di luar kelas.

\section{Penutup}

Uraian di atas, penulis memberikan gambaran bahwa komunikasi matematis merupakan salah satu jantung dalam pembelajaran, sehingga perlu menumbuhkembangkan dalam aktivitas pembelajaran matematika. Hal ini di perkuat oleh Badan Standar Nasional Pendidikan (2006) menyebutkan kemampuan dasar SD sampai dengan SMA, bahwa komunikasi matematis merupakan salah satu kemampuan dasar yang perlu diupayakan peningkatannya sebagaimana kemampuan dasar lainnya, seperti kemampuan bernalar, kemampuan pemahaman matematis, kemampuan pemecahan masalah, kemampuan komunikasi matematis dan koneksi, serta kemampuan representasi matematis.

Dengan demikian, makna membangun kemampuan komunikasi bagi guru adalah sebagai "teaching how to learn mathematics", sedangkan bagi siswa bermakna sebagai "learning how to learn mathematics" (Jacob, $2003: 4$ ).

\section{Daftar Rujukan}

Artzt, A.F. (1996).«Developing Problem Solving Behaviors by Assessing Communication In Cooperative Learning". In P.C Elliott, and M.J. Kenney (Eds.). 1996 Yearbook. Communication in lvlathematics, K-12 and Beyond. USA: NCTM.

Baroody. A.J. 1993. Problem Solving, Reasoning, and Communicating. New York: Macmillan Publishing.

Cai, Jinfa. 1996. Assesing Students' Mathematical Communication. Official Journal of the Science and Mathematics Volume 96 No 5 Mei 1996. Hal: 238-246.

Cai Jinfa \& Patricia. 2000. Fostering Mathematical Thinking through Multiple Solutions. Mathematics Teaching in the Middle School Vol 5 No 8 April

Clark, K. K., et.al. (2005). Strategies for Building Mathematical Communication in the Middle School Classroom: Modeled in Professional Development, Implemented in the Classroom. CIME (Current Issues in Middle Level Education) (2005)11(2), 1-12 
Greenes, C. \& Schulman, L. (1996). "Communication Processes in Mathematical Explorations and Investigations". In P. C. Elliott and M. J. Kenney (Eds.). 1996 Yearbook. Communication in Mathematics. K-12 and Be.vond. USA: NCTM.

Huggins, B., \& Maiste, T.(1999). Communication in Mathematics. Master's Action Research Project, St. Xavier University \& IRI/Skylight.

Jacob, C. (2003). Matematika Sebagai komunikasi. Makalah pada Seminar Tingkat Nasional. FPMIPA UPI Bandung. Tidak dipublikasikan

Kramarski, B. (2000). "The effects of different instructional methods on the ability to communicate mathematical reasoning". Proceedings of the 24th conference of the international group for the psychology of mathematics education. Japan.

Lauren \& Hunting. 1999. Relating fraction and Decimals: Listening to Students Talk. Mathematics Teaching in The Middle School. Vol 4 No 5 Februari 1999. Hal: 318321

Marson, J. (2000). Researching Your Own Practice,. The Discipline of Noticing.: Noticing and Professional Development: Hal: 139-148. London and New York

National Council of Teachers of Mathematics. 1989. Curriculum and Evaluation Standards for School Mathematics. Reston, Virginia: NCTM.

National Council of Teachers of Mathematics. 2000a. Principles and Standards for School Mathematics. NCTM: Reston VA.

National Council of Teachers of Mathematics. 2000b. learning Mathematics for A New Century. 2000 Yearbook NCTM: Reston VA.

National Science Foundation (NSF). 1998. Mathematics in Context: Teachers Resource and Implementation Guide. Chicago: Encyclopedia Britanica Ed.

NCTM (2000). Principles and Standards for School Mathematics, Reston, Virginia.

Patricia. C. Alcaro, dkk. 2000. Fractions Attack! Children Thinking and Talking Mathematically. Teaching Children Mathematics Vol 6 No 9 Mei 2000. Hal: 562567

Pugalee, K David. 2001. Using Communication to Develop Students' Mathematical Literacy. Mathematics Teaching in The Middle School Vol 6 No 5 Januari. Hal: 296299

Sandra L Atkins. 1999. Listening to Students. Teaching Children Mathematics. Vol 5 No 5 Januari. Hal: 289-295

Silver, E.A. \& Smith, M.S. (1996). "Building Discourse Communities in Mathematics Classrooms: A Worthwhile but Challenging Journey". In P.c. Elliott, dan M.J. Kenney. (Eds.). 1996 Yearbook. Communication in Mathematics. K-12 and Beyond. Reston, VA: NCTM

Tandaliling, (2011),. Peningkatan Pemahaman dan Komunikasi Matematis serta Kemandirian Belajar Siswa SMA Melalui Strategi PQ4R dan Bacaan Refutation Text. Disertasi SPs.UPI Tidak diterbitkan 